\title{
Development of diurnal micturition pattern in mice after weaning.
}

\section{$\operatorname{AUTHOR}(\mathrm{S})$ :}

Negoro, Hiromitsu; Kanematsu, Akihiro; Matsuo, Masahiro; Okamura, Hitoshi; Tabata, Yasuhiko; Ogawa, Osamu

\section{CITATION:}

Negoro, Hiromitsu ... [et al]. Development of diurnal micturition pattern in mice after weaning.. The Journal of urology 2013, 189(2): 740-746

\section{ISSUE DATE:}

2013-02

URL:

http://hdl.handle.net/2433/169698

\section{RIGHT:}

(c) 2013 American Urological Association Education and Research, Inc. Published by Elsevier Inc.; この論文は出版社版でありません。引用の際には出版社版をご確認ご利用 ください。; This is not the published version. Please cite only the published version. 


\section{Development of diurnal micturition pattern in mice after weaning}

Hiromitsu Negoro ${ }^{1,2}$, Akihiro Kanematsu ${ }^{1,3}$, Masahiro Matsuo ${ }^{4}$, Hitoshi Okamura ${ }^{4}$, Yasuhiko Tabata ${ }^{2}$, and Osamu Ogawa ${ }^{1} *$

${ }^{1}$ Department of Urology, Kyoto University, Graduate School of Medicine, Sakyo, Kyoto 606-8507 Japan;

${ }^{2}$ Department of Biomaterials, Institute for Frontier Medical Sciences, Kyoto University, Sakyo, Kyoto 606-8507 Japan;

${ }^{3}$ Department of Urology, Hyogo College of Medicine, Nishinomiya, Hyogo 663-8501 Japan;

${ }^{4}$ Department of Systems Biology, Graduate School of Pharmaceutical Sciences, Kyoto University, Sakyo, Kyoto 606-8501, Japan;

Running head: Development of micturition in mice (34 characters with space)

Keywords: Development; Diurnal variation; Micturition; Mouse; Urination

Abbreviations: UVVM, urine volume voided per micturition; aVSOP, automated voided stain on paper; rPSD, relative power spectral density 


\section{Abstract}

Purpose: Development of micturition in mice has been poorly studied because of the minute urine volume voided per micturition (UVVM). We aimed to characterize development of the micturition pattern in young mice.

Material and Methods: Micturition in young mice immediately after weaning (C57BL/6 strain; males, $\mathrm{n}=5$; females, $\mathrm{n}=4,3$ week-old) and in adult mice ( $\mathrm{n}=5$ both sexes, aged 9-10 week-old), was recorded by the automated voided stain on paper (aVSOP) method. Micturition data were obtained under 12-hour light/dark cycles in young mice for 16 days and in adult mice for 4 days. Diurnal variations were assessed during 8 hours until the first-void after lights-off and those until lights-on. Twenty-four-hour rhythmicity of urinary frequency was calculated for 4-day data at the beginning, and also at the end for young mice, as well as the 4-day data for adult mice, by $\chi^{2}$ periodogram and relative power spectral density.

Results: Mean frequency ranged from 20-30 times/day. Total urine volume/day and mean UVVM/day increased with age. The diurnal rhythm of frequency matured to adult levels with development, which was primarily achieved by maturation of diurnal 
variation of urine volume in male mice followed by female mice. Diurnal variation of UVVM was indistinct at the initial stage and gradually matured toward adult levels.

Conclusions: The aVSOP method was used to record micturition development in young mice, and generated data corresponding to frequency-volume charts in humans. Our findings could lead to establishment of a mouse model of developmental micturition disorders, such as nocturnal enuresis. 
DEVELOPMENT of micturition during infancy and childhood is characterized by two factors ${ }^{1}$. One factor is an increase in storage capacity by the urinary bladder, associated with an increase in urine production by the kidney, and the other factor is achievement of continence and voluntary urination. In addition, diurnal rhythms in urine production and functional bladder capacity avoid involuntary loss of urine or disturbance of sleep by micturition in healthy adults. Immaturity in the development of micturition results in nocturnal enuresis or daytime incontinence, which are the most common diseases in pediatric urology clinics $^{2-4}$. However, the pathophysiology of these conditions has not been fully elucidated yet, particularly from the standpoint of basic science.

This may be due, in part, to the lack of an appropriate animal model for postnatal development of urination. For example, in spite of compelling epidemiological evidence indicating the involvement of genetic background for nocturnal enuresis ${ }^{5,6}$, genetically modified mice have rarely been employed as tools for investigation ${ }^{7}$, because the precise recording of micturition in young mice has not been able to be achieved. Measurement of micturition in mice is challenging ${ }^{8-10}$, because even in adult mice, urine volume voided per micturition (UVVM) is too small to be continuously and accurately assessed by conventional methods, and UVVM of young mice is much smaller than that in adults. 
The current study used a micturition recording system named the automated voided stain on paper (aVSOP) method, which was devised by our group to record the micturition of a free-moving mouse fed ad libitum for several days ${ }^{11}$. We showed how young mice develop an adult pattern of micturition immediately after weaning.

\section{MATERIAL AND METHODS}

\section{Experimental Animals}

We purchased young C57BL/6 mice immediately after weaning (aged 3 weeks) and adult C57BL/6 mice (aged 9-10 weeks) from Japan Lab Animals Co., Ltd. (Osaka, Japan). Animals were treated in accordance with NIH animal care guidelines, and the Kyoto University Animal Experiment Committee approved all animal experiments.

\section{Micturition analysis}

We used aVSOP, which is a micturition recording system for the mouse, as previously described $^{11}$ with simultaneous recording of actogram. Machines were designed and 
produced in collaboration with Real-designs Co., Ltd (Kyoto, Japan). Rolled laminated filter paper, pre-treated to turn the edge of urine stains deep purple, was wound up at a speed of $10 \mathrm{~cm} / \mathrm{h}$ under a water-repellant wire lattice. Urine stains were counted and traced to convert micturition volume by the formula of a standard curve, calculated by the correlation of normal saline and the stained area, ranging from 10 to $800 \mu 1$ $\left(\mathrm{R}^{2}=0.9994\right)$. The mice were kept in a cage with the dimensions $75 \times 160 \times 75 \mathrm{~mm}$ (height $\times$ depth $\times$ width), with free access to water and food, measured under 12-hour light and 12-hour dark conditions. The amount of water and food taken was not counted. Total urine volume per hour was estimated by dividing the volume with the time interval between the given and the preceding voiding (filling time) when the filling time was more than 1 hour ${ }^{12}$. The total amount of micturitions analyzed was 1950 in five young male mice and 1595 in four young female mice for 16 days, and 443 in five adult male mice and 509 in five adult female mice for 4 days.

\section{Statistical analysis}

Circadian amplitude of frequency was calculated as the normalized peak of the relative power spectral density (rPSD) by Fourier transform using Clocklab software 
(Actimetrics, Evanston, IL). Paired $t$-tests for a day-night change in micturition data and unpaired $t$-tests for a difference in sexes were calculated using SPSS ver.11.0.1J software (SPSS inc., Chicago, IL). Two-way repeated measures ANOVA was used for differences in average urine volume corrected for body weight between the time points, and sexes. A $P$ value $<0.05$ was accepted as significant.

\section{RESULTS}

\section{The aVSOP method enables recording of micturition in young mice}

The aVSOP method continuously collects urine spots dropped on laminated filter paper by a free-moving mouse (Fig. 1A, B). The edges of voided spots turn deep purple and remain so (Fig. 1B), which enable us to calculate UVVM from the stained area.

To assess the development of micturition, we measured micturition in male and female C57BL/6 mice immediately after weaning and compared it with that in adults (Fig. 2A-C). UVVM of young mice developed from less than $50 \mu 1$ in the immediately after weaning, which was successfully detected by the aVSOP method. The simultaneous recording of mice movements as an actogram showed the nocturnal 
characteristics of mice (Fig. 2D).

\section{Development of the micturition pattern per day}

First, we analyzed the data as daily sums for three micturition parameters: total urination frequency, total urine volume, and mean UVVM per day (Fig. 3A-C). Total urination frequency was relatively constant during the observational period, ranging from 20-30 times per day; however, there was a transient increase in female mice on the $7^{\text {th }}, 8^{\text {th }}$ and $9^{\text {th }}$ days after weaning (Fig. 3A), but this was not observed in male mice. Total urine volume per day increased with age throughout the observational period in both males and females (Fig. 3B). Average urine volume corrected for body weight during last 2 days of experiments were slightly higher than that during the first 2 days, $(140.0 \pm 6.9$ versus $102.7 \pm 10.5 \mu \mathrm{l} / \mathrm{g}$, respectively. $p<0.05$ by two-way repeated measures ANOVA, $F(1,7)=11.1$, while there was no significant difference between male and female. As body weight was measured only at the beginning and end of the experiment, it is unclear when this increase occurred. The mean UVVM per day also increased with age. UVVM in female mice increased more slowly compared with male mice, which was reflected in the transient increase in total frequency on the $7^{\text {th }}, 8^{\text {th }}$ and 
$9^{\text {th }}$ days.

\section{Development of diurnal micturition variation}

We analyzed the data to determine diurnal micturition variations, i.e., day-night differences in micturition. Because mice are nocturnal animals, their urination pattern is the opposite to that in humans. In adult mice, more urine is produced during the dark phase (active phase for mice) than during the light phase (sleep phase for mice), and more urine is stored in the bladder during the light phase than in the dark phase ${ }^{11}$. In this study, the variation was assessed during 8 hours until the first void after the lights were turned off (light phase), and during 8 hours until the lights were turned on (dark phase), under 12-hour light-dark cycles (Fig. 4A-C). The remaining 8 hours were considered as transitional periods between the active and sleep phases. Diurnal variation of urinary frequency was noted at the end of the observational period in both sexes, although it appeared earlier in male than in females (Fig. 4A). Diurnal variation in urine production, with more urine produced in the dark phase than in the light phase, was remarkable from the first week after weaning in male mice, but it appeared later in female mice (Fig. 4B). The diurnal variation of UVVM was not as prominent as that of 
urine production, but gradually emerged after 1 week of weaning in both male and female mice (Fig. 4C). In summary, we found that the diurnal variations in frequency and urine volume were established in male mice, but not in female mice immediately after weaning, and the development of diurnal variation in frequency and urine volume preceded that of UVVM.

\section{Diurnal rhythm analysis of urinary frequency}

Moreover, we focused on the development of diurnal variation of frequency, and analyzed it mathematically as a 24-hour rhythmicity, using the $\chi^{2}$ periodogram and relative 24-hour power spectral density (rPSD) (Fig. 5A-C). The term rPSD indicates the relative amplitude of rhythmicity calculated by Fourier transform. These analyses show the relative intensity of rhythmicity in 24 hours, i.e., the diurnal rhythm ${ }^{11,13}$. The $\chi^{2}$ periodogram showed that the amplitude peaked at the 24 -hour period during D2-5 (day 2 to 5) as well as D13-16 after weaning in male mice, while the peak in female mice during D2-5 was less prominent (Fig. 5A). The diurnal amplitude demonstrated a sharp peak at the 0.042 cycle/hour, which indicates the 24 hour rhythm as one cycle/24 hours (Fig. 5B). To quantify the difference in the 24-hour rhythmicity of urinary 
frequency between different ages, the intensity of the 0.042 cycle/hour was normalized by a sum of all intensities from 0.008 to 29.99 cycle/hour: rPSD. The rPSD of male mice did not significantly change between D2-5, D13-16, and adults, while that of females significantly increased from D2-5 to D13-16 to adults $(P<0.05$ by $t$-test) (Fig. 5C). These data indicate that the diurnal rhythm of frequency was almost established at weaning in male mice, while in female mice, it was less prominent and gradually matured toward the adult level with age.

\section{DISCUSSION}

This is the first study reporting the precise development of the micturition pattern in normal mice, as a dataset that corresponds to the frequency-volume charts in humans.

The central finding of this study is a distinct pattern of maturation in development of micturition in young mice. Although rodents have been used as an animal model of micturition, little is known regarding postnatal development, because of technical difficulties in assessing their urination. Even in rats, which have been commonly used for functional bladder studies because of their relatively larger size, there has been little developmental analysis. Using a newly devised aVSOP system, which can detect a 
small amount of urine, with as little as $10 \mu \mathrm{l}$ by specific filter paper with backside lamination, we succeeded in recording the urination pattern in young mice, and examined normal bladder development. Although murine development may not exactly correspond to that of humans, mice after weaning, aged 3 to 5 weeks old, may be equivalent to post-toilet-trained children before adolescence in humans, in the sense that they can cope with their urination as an independent individual but have not fully acquired the adult pattern of urination.

One specific finding of this study is that the mean urinary frequency per day was relatively constant in young and adult mice. This was maintained by an increase in bladder capacity following urine production with a certain time lag. Therefore, when UVVM of female mice could not catch up with the urine production rate on days 7, 8, and 9, the mean urination frequency transiently increased.

The other specific finding in the current study was establishment of a day-night rhythm. This is an important axis for analyzing micturition behavior, since the disturbance of such rhythms in humans results in nocturnal enuresis in children, or nocturia in the elderly. The diurnal change of bladder compliance has been analyzed by cystometrogram in adult mice under anesthesia ${ }^{14}$, but it is still challenging for young mice. In addition, we should note that anesthesia may affect the bladder capacity and 
diurnal behavior ${ }^{15,16}$. We have previously found that the micturition frequency in free-moving adult rodents also shows a rhythmic diurnal change ${ }^{11}$. This change is generated in adult mice by inverted rhythms of urine production and functional bladder capacity represented by UVVM. Increased functional capacity and decreased urine production rate during the sleep phase protect the fast sleep against micturition both in rodents and in humans ${ }^{12,17-19}$. The present study showed that the diurnal micturition rhythm is initially generated by the rhythm of urine production, and is further strengthened by changes in bladder capacity during a later phase of development. Since actogram indicated that diurnal change in body movement has already been established throughout the observation period, the present results may indicate that diurnal change in bladder capacity is a phenomenon acquired at relatively later stage of postnatal development. This is an important point since such delay in bladder maturation causes a mismatch between bladder capacity and urine production during sleep phase, which characterizes nocturnal enuresis in humans ${ }^{17}$. This phenomenon could be potentially associated with the diurnal bladder rhythm itself ${ }^{11}$ and or with arousal state of young mice $^{20}$, and warrants further investigation.

Differences in sex in the development of micturition were an unexpected finding in our study. In contrast to the gradual development in female mice, diurnal variations in 
urine production rate and frequency were almost established soon after weaning in male mice. It is unclear what caused such sex differences, and whether differences in mice can provide insight into human pathophysiology of micturition ${ }^{21}$. However, our findings should be taken into account for analyzing micturition behavior in male and female mice, as previous reports have shown sex differences in phenotype in rodents and humans ${ }^{22-25}$.

The aVSOP system has a promising translational potential, because it retrieves a data set corresponding to frequency-volume charts in human clinics. In modern management of pediatric lower urinary tract symptoms, the charts are now postulated as a central tool for evaluating patients, according to an International Children's Continence Society committee ${ }^{26}$. The aVSOP method enables interpretation of data in the mouse in a similar manner as for physicians treating patients in clinics. This method could provide a platform to analyze murine micturition behavior to study urinary disturbances in children, including highly prevalent conditions such as nocturnal enuresis, daytime urinary incontinence, overactive bladder and underactive bladder ${ }^{27}$. Accumulating evidence suggests involvement of genetic links to familial enuresis, although these studies did not designate the responsible gene ${ }^{6}$. Our system could become a powerful 
tool to determine function of any given candidate genes, if genetically-modified animals corresponding to human genetic anomalies could be generated.

\section{CONCLUSIONS}

Our aVSOP system was successful for measuring micturition development in young mice. These data could be used for establishing mouse models of developmental micturition disorders, such as nocturnal enuresis.

\section{ACKNOWLEGEMNENTS}

This work was supported by a Grant-in-Aid for Scientific Research (21390439 and 23659756) from the Japan Society for the Promotion of Science (JSPS). We thank Y.

Sugino and Y. Kimura for their kind advice to develop the aVSOP system, N. Kawakami for editing a macro of ImageJ and A. Negoro for assisting with data collection associated with aVSOP.

\section{REFERENCES}


1. Jansson UB, Hanson M, Sillen U et al: Voiding pattern and acquisition of bladder control from birth to age 6 years--a longitudinal study. J Urol 2005; 174: 289.

2. Robson WL: Clinical practice. Evaluation and management of enuresis. N Engl J Med 2009; 360: 1429.

3. Neveus T: Diagnosis and management of nocturnal enuresis. Curr Opin Pediatr 2009; 21: 199.

4. Kajiwara M, Inoue $\mathrm{K}$, Usui et al: The micturition habits and prevalence of daytime urinary incontinence in Japanese primary school children. J Urol 2004; 171: 403 .

5. von Gontard A, Heron J and Joinson C: Family history of nocturnal enuresis and urinary incontinence: results from a large epidemiological study. J Urol 2011; 185: 2303.

6. von Gontard A, Schaumburg H, Hollmann E et al: The genetics of enuresis: a review. J Urol 2001; 166: 2438.

7. Andersson KE, Soler $\mathrm{R}$ and Fullhase $\mathrm{C}$ : Rodent models for urodynamic investigation. Neurourol Urodyn 2011; 30: 636.

8. Sugino Y, Kanematsu A, Hayashi $\mathrm{Y}$ et al: Voided stain on paper method for analysis of mouse urination. Neurourol Urodyn 2008; 27: 548. 
9. Birder LA, Nakamura Y, Kiss $\mathrm{S}$ et al: Altered urinary bladder function in mice lacking the vanilloid receptor TRPV1. Nat Neurosci 2002; 5: 856.

10. Wood R, Eichel L, Messing EM et al: Automated noninvasive measurement of cyclophosphamide-induced changes in murine voiding frequency and volume. $\mathrm{J}$ Urol 2001; 165: 653.

11. Negoro H, Kanematsu A, Doi $\mathrm{M}$ et al: Involvement of urinary bladder Connexin43 and the circadian clock in coordination of diurnal micturition rhythm.

Nat Commun 2012; 3: 809.

12. Van Hoeck K, Bael A, Lax $\mathrm{H}$ et al: Circadian variation of voided volume in normal school-age children. Eur J Pediatr 2007; 166: 579.

13. Meredith AL, Wiler SW, Miller BH et al: BK calcium-activated potassium channels regulate circadian behavioral rhythms and pacemaker output. Nat Neurosci 2006; 9: 1041.

14. Dorr W: Cystometry in mice--influence of bladder filling rate and circadian variations in bladder compliance. J Urol 1992; 148: 183.

15. Ghoniem GM, Shoukry MS and Monga M: Effects of anesthesia on urodynamic studies in the primate model. J Urol 1996; 156: 233.

16. Dispersyn G, Pain L and Touitou Y: Circadian disruption of body core 
temperature and rest-activity rhythms after general (propofol) anesthesia in rats. Anesthesiology 2009; 110: 1305.

17. Van Hoeck K, Bael A, Lax $\mathrm{H}$ et al: Urine output rate and maximum volume voided in school-age children with and without nocturnal enuresis. J Pediatr 2007; 151: 575.

18. Weiss JP, Blaivas JG, Stember DS et al: Evaluation of the etiology of nocturia in men: the nocturia and nocturnal bladder capacity indices. Neurourol Urodyn 1999; 18: 559 .

19. Herrera GM and Meredith AL: Diurnal variation in urodynamics of rat. PLoS One 2010; 5: e12298.

20. Kiddoo DA, Valentino RJ, Zderic $S$ et al: Impact of state of arousal and stress neuropeptides on urodynamic function in freely moving rats. Am J Physiol Regul Integr Comp Physiol 2006; 290: R1697.

21. Forsythe WI and Redmond A: Enuresis and spontaneous cure rate. Study of 1129 enuretis. Arch Dis Child 1974; 49: 259.

22. Lin LC, Lewis DA and Sibille E: A human-mouse conserved sex bias in amygdala gene expression related to circadian clock and energy metabolism. Mol Brain 2011; 4: 18. 
23. Textoris J, Ban LH, Capo C et al: Sex-related differences in gene expression following Coxiella burnetii infection in mice: potential role of circadian rhythm. PLoS One 2010; 5: e12190.

24. Cornelissen LL, Misajet B, Brooks DP et al: Influence of genetic background and gender on bladder function in the mouse. Auton Neurosci 2008; 140: 53.

25. Chun AL, Wein AJ, Harkaway $\mathrm{R}$ et al: Comparison of urinary bladder function in sexually mature and immature male and female rats. J Urol 1990; 143: 1267.

26. Neveus T, von Gontard A, Hoebeke P et al: The standardization of terminology of lower urinary tract function in children and adolescents: report from the Standardisation Committee of the International Children's Continence Society. J Urol 2006; 176: 314.

27. Ballek NK and McKenna PH: Lower urinary tract dysfunction in childhood. Urol Clin North Am 2010; 37: 215. 


\section{FIGURE LEGENDS}

Figure 1. The aVSOP method. (A) Cartoon showing a side view of the aVSOP method.

When a mouse urinates, the urine drops on the paper and produces a stain. (B)

Photographs showing the front view of aVSOP system (upper panel) and a representative urine stain with a deep purple edge (lower panel, indicated by arrow heads). 
Figure 2. Representative time-course charts of young and adult mice obtained by the aVSOP method. (A) A representative photograph of urine stains on paper used in a young male mouse. The bar indicates $10 \mathrm{~cm}$, corresponding to $1 \mathrm{~h}$. Representative charts of UVVM of a mouse immediately after weaning (left panel) and of an adult mouse (right panel) for male in (B) and for female in (C). No marked difference in body weight was observed between young male and female mice immediately after weaning $(8.13 \pm 0.16 \mathrm{~g}$ versus $8.31 \pm 0.18 \mathrm{~g}$, respectively). (D) Representative actograms of a young male (left) and a female (right) mouse. Each following day was double-plotted. 
Figure 3. Developmental analyses of young mice immediately after weaning compared with those of adult mice. (A) Urinary frequency per day was largely constant between young and adult male mice, although there was a transient increase at days 7, 8 and 9 after weaning in young female mice. (B) Urine volume per day increased with age until the end of the study. (C) Mean UVVM per day also increased with age. ${ }^{*} p<0.05$ versus male mice on the same day by $t$-test. Error bars represent SD. 
Figure 4. Diurnal variation of the micturition pattern in young mice immediately after weaning compared with those of adult mice. (A) Urinary frequency per 8 hours in the light and dark phases. Development of diurnal variation started soon after weaning in young male mice. (B) Urine volume per 8 hours just before the lights were turned on (dark) and until the first void of the dark phase (light). Achievement of diurnal variation was observed immediately after weaning in male mice. (C) UVVM per 8 hours in the light and dark phases. Diurnal variation was not initially observed but gradually developed in both male and female mice. ${ }^{*} p<0.05$ versus the light phase in A and B, and the dark phase in $\mathbf{C}$ by paired $t$-test. Error bars represent SD. 
Figure 5. Sex differences in the development of diurnal rhythm in urinary frequency.

(A) The mean $\chi^{2}$ periodogram of frequency in young mice for 4 days at $2-5$ days (D2-5) and 13-16 days (D13-16) after weaning, and in adult mice. A 24-hour periodicity (indicated by arrow heads) was less prominent in females on D2-5, and became remarkable on D13-16. (B) The 24-hour amplitude (0.042 cycles per hour, indicated by arrow heads) was quantified as relative power. (C) The diurnal rhythmicity of frequency was significantly increased in female mice with age, although it was relatively constant in male mice. ${ }^{*} p<0.05$ versus D2-5 and $\dagger p<0.05$ versus D13-16, by $t$-test. Error bars represent SE. 
A
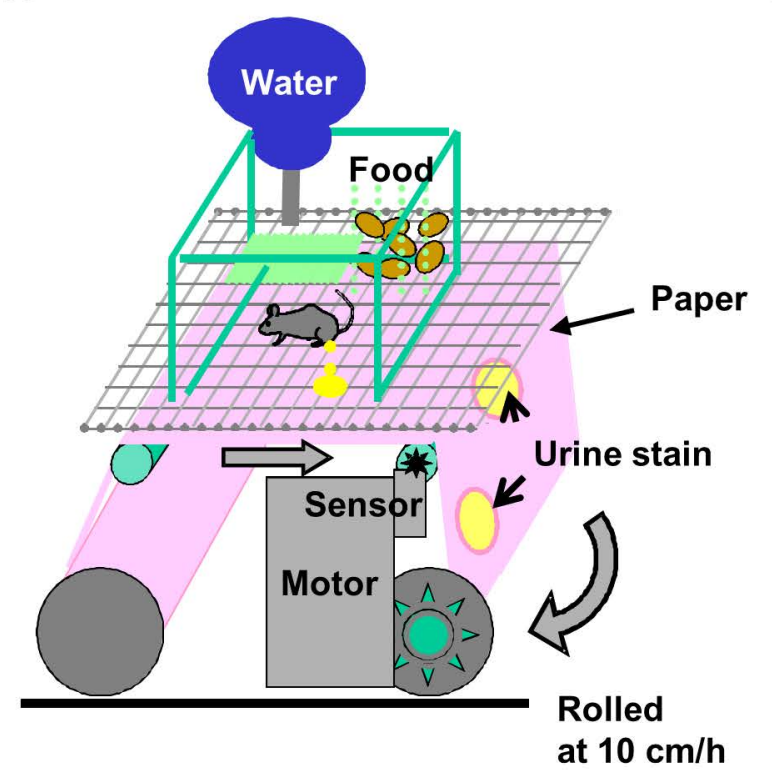

B

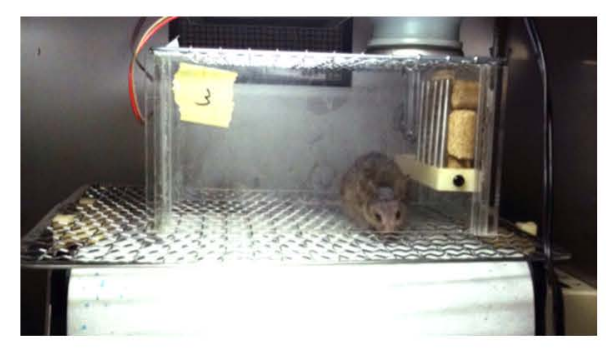

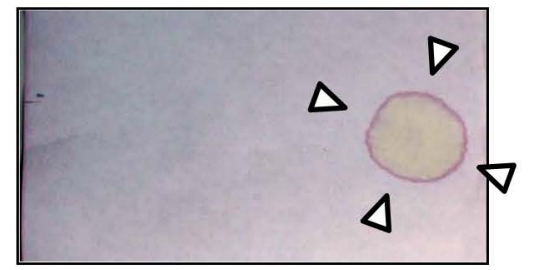


A

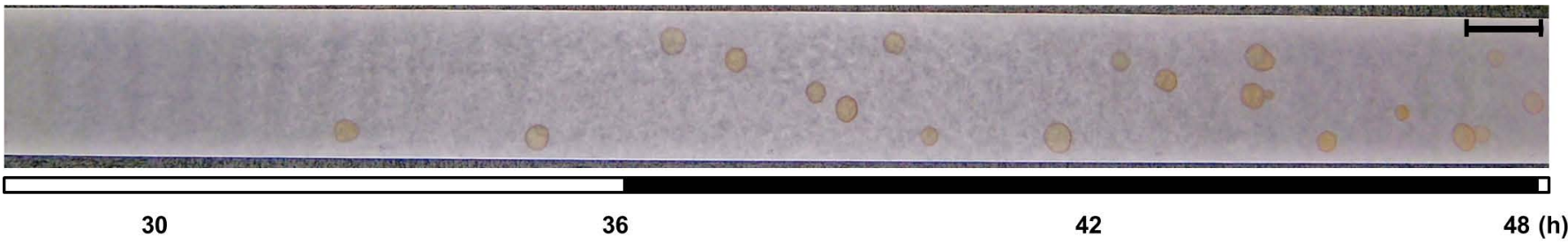

B

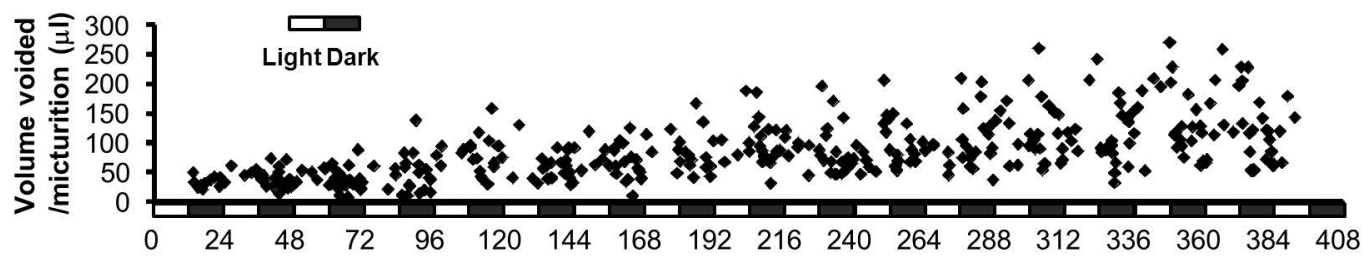

C

D
Female young mouse

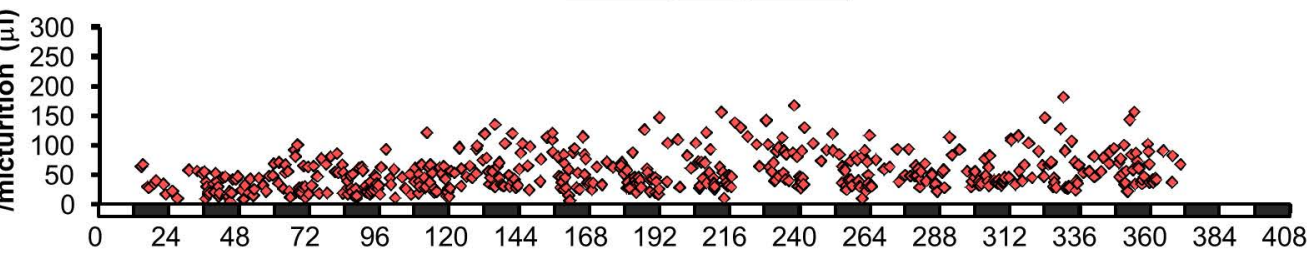

Male young mouse

808 (h)
Male adult mouse

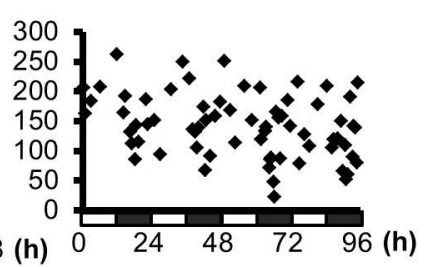

\section{Female adult mouse}

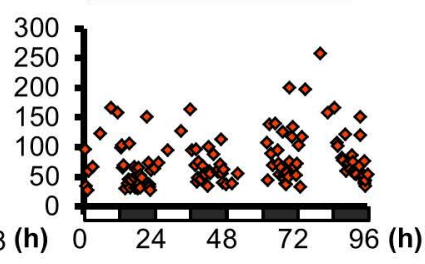

\section{Male young mouse}

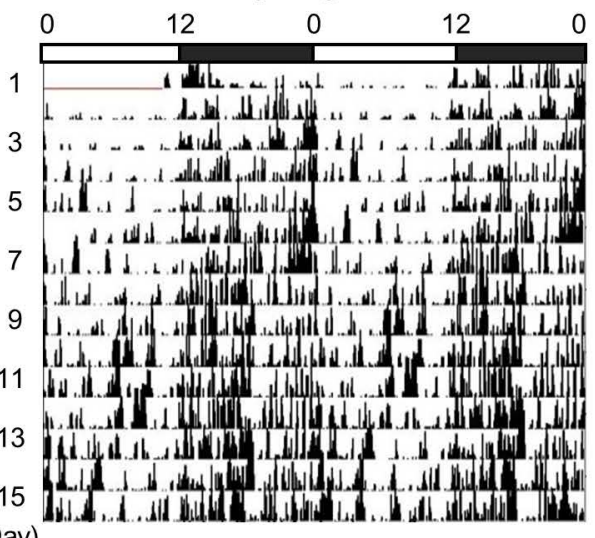

\section{Female young mouse}

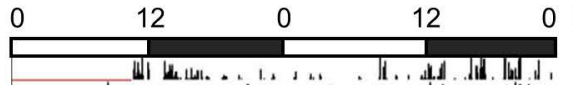

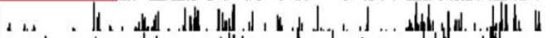

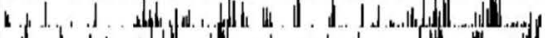

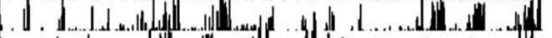

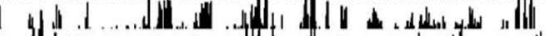

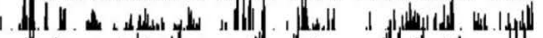

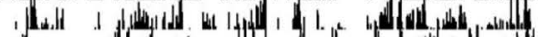

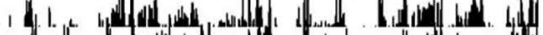

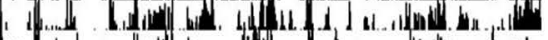

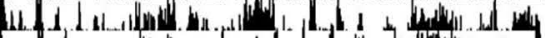

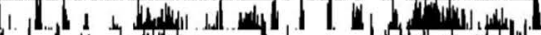

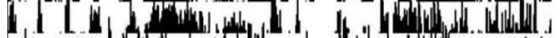

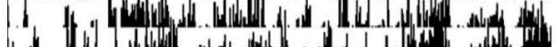

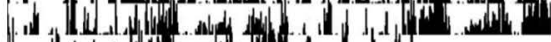

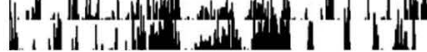


A

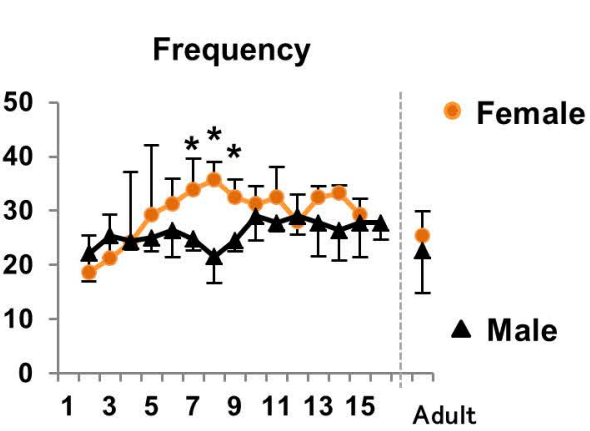

B

( $\mu \mathrm{I}) \quad$ Urine volume

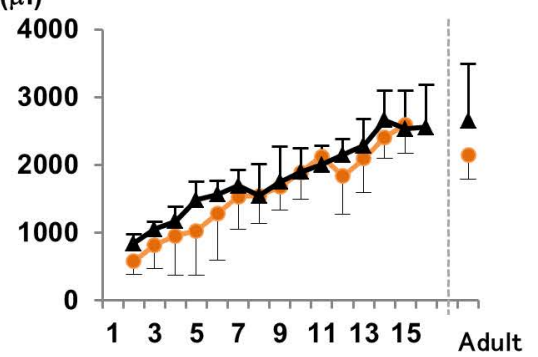

C

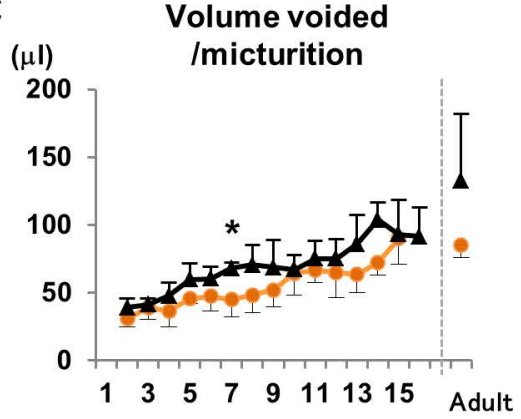


A

\section{Frequency}
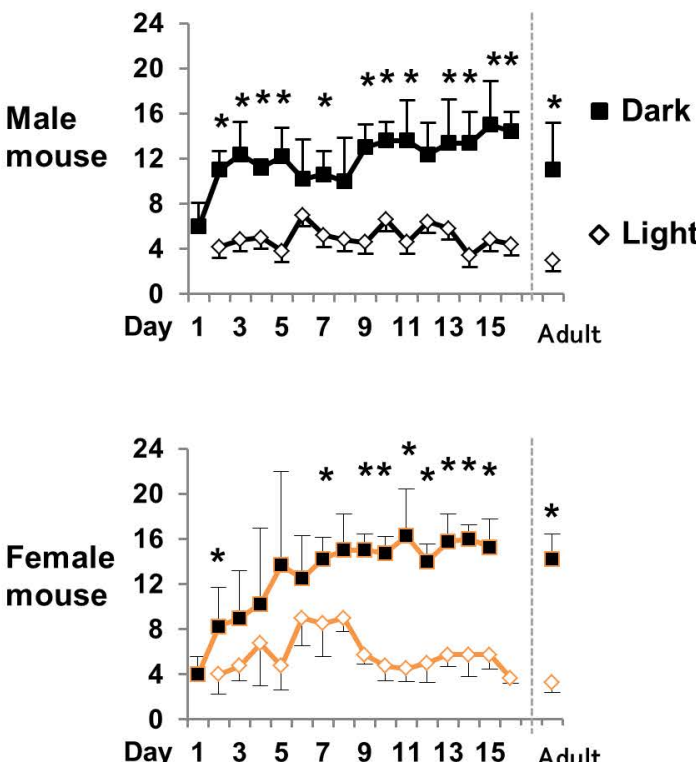

B

$$
\text { ( } \mu l)
$$
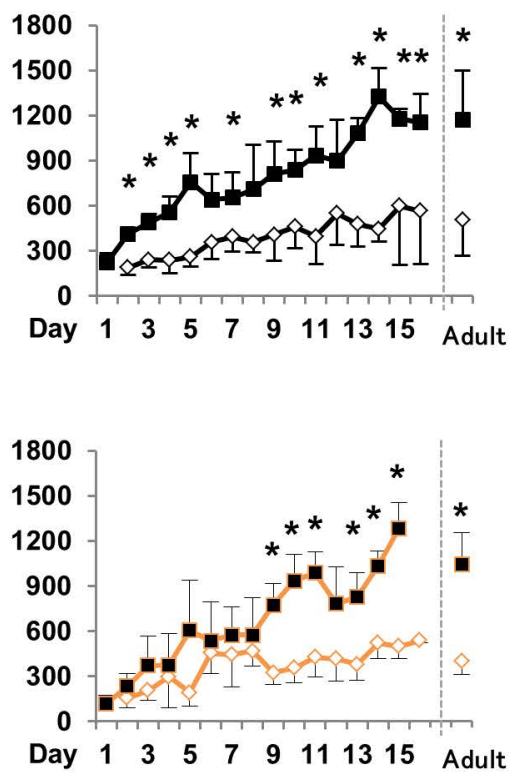

C

( $\mu \mathrm{I})$

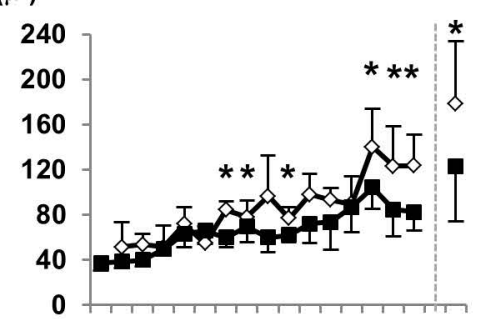

$\begin{array}{llllllllll}\text { Day } & 1 & 3 & 5 & 7 & 9 & 11 & 13 & 15 & \text { Adult }\end{array}$

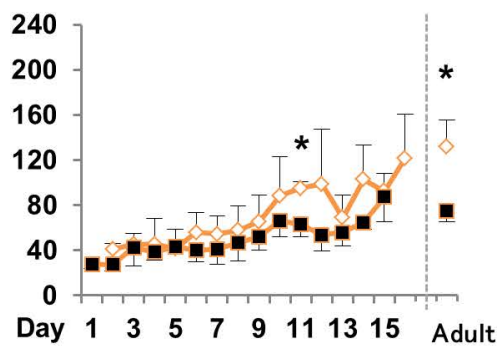



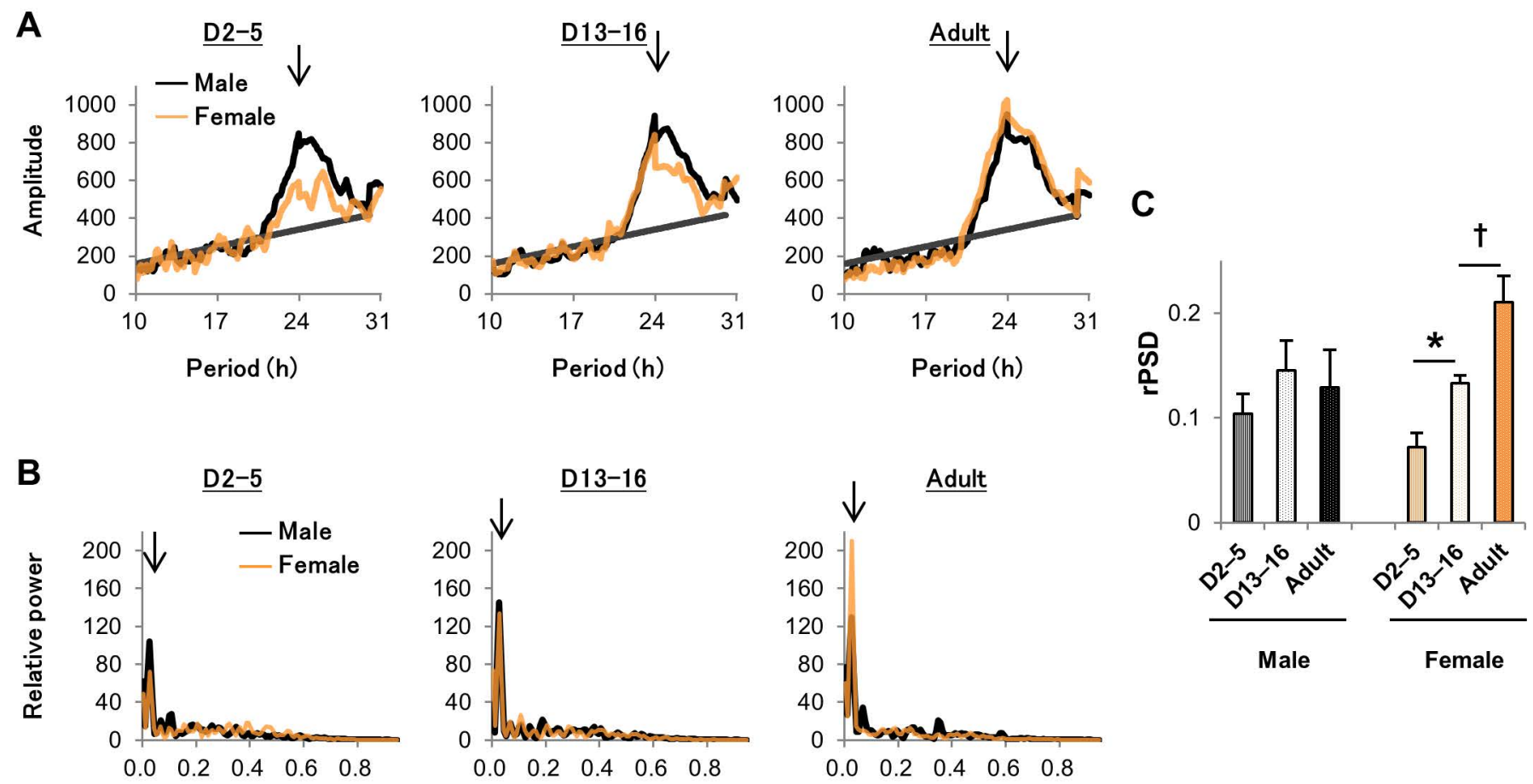

Frequency (cycles/hour)

Frequency (cycles/hour)

Frequency (cycles/hour) 